\title{
MANAJEMEN INOVASI SEBAGAI SOLUSI KEBIJAKAN TERHADAP PERSOALAN SAMPAH PLASTIK DI KOTA SAMARINDA
}

\author{
(MANAGEMENT AS A SOLUTION FOR POLICY TO SOLVE THE \\ PROBLEM OF PLASTIC WASTE IN \\ SAMARINDA CITY)
}

\author{
Thomas Robert Hutauruk
}

\author{
Sekolah Tinggi Ilmu Manajemen Indonesia Samarinda \\ Jalan M. Yamin No. 78 RT. VII Samarinda \\ Email: thomas_huta@yahoo.com
}

Diterima: 30 April 2019; Direvisi: 8 Mei 2019; Disetujui: 9 Mei 2019

\begin{abstract}
This study aims to find out innovative ways that might be done in overcoming the problem of plastic Waste in Samarinda City. The method used a survey so that the data used are sources from primary and secondary data from previous studies that were analyzed qualitatively using policy analysis methods focused synthesis (focused synthesis) to produce policy formulations in accordance with the objectives of the study. The results of the study indicate that the government's policy to stop giving plastic bag to consumers is not appropriate because it deviates from the goals to be achieved, and actually has an impact on increasing the use of plastic. So that the recommendations given are the necessity of providing adequate infrastructure, and monitoring the government for businesses to increase the ability of innovation in overcoming the problem of plastic Waste in the future.
\end{abstract}

Keywords: Innovative, Policy, Samarinda, Plastics Waste

\begin{abstract}
ABSTRAK
Penelitian ini bertujuan untuk mengetahui cara-cara inovatif yang mungkin dilakukan dalam mengatasi persoalan sampah plastik yang ada di Kota Samarinda. Metode yang digunakan adalah survey sehingga data yang digunakan adalah berumber pada data primer dan data sekunder dari penelitian-penelitian sebelumnya yang dianalisis secara deskriptif kualitatifmenggunakan metode analisis kebijakan model sintesis terfokus (focused synthesis) untuk menghasilkan formulasi kebijakan sesuai dengan tujuan penelitian. Hasil penelitian menunjukkan bahwa kebijakan pemerintah untuk menghentikan pemberian kantong plastik pada konsumen kurang tepat karena menyimpang dari sasaran yang ingin dicapai, dan justru berdampak pada peningkatan penggunaan palstik. Sehingga rekomendasi yang diberikan adalah perlunya penyediaan sarana prasarana yang memadai, dan penadmpingan pemerintah terhadap pelaku usaha untuk meningkatkan kemampuan inovasidalam mengatasi masalah sampah plastik di masa mendatang.
\end{abstract}

Kata kunci: Inovatif, Kebijakan, Plastik, Samarinda, Sampah

\section{PENDAHULUAN}

Penggunaan plastik di Indonesia cukup tinggi dikarenakan bahan palstik memiliki sifatsifat antara lain: ringan, fleksibel, tahan kelembaban, kuat, dan relatif murah. Menurut Indonesia Solid Waste Association (InSWA), produk sampah plastik Indonesia sekitar 5,4 juta ton per tahun. Dalam pemberitaan Kompas.com tanggal 19 Agustus 2018 mengutip pernyataan Menteri Kalautan dan Perikanan Republik Indonesia, Susi Pujiastuti bahwa Indonesia penyumbang plastik terbesar kedua di Dunia. Ditambahkan bahwa berdasarkan data BPS sekitar 3,2 juta ton dari 64 juta ton per tahun sampah plastik di Indonesia dibuang ke laut dan menimbulkan pencemaran. Pernyataan Menteri tersebut diadopsi dari data yang dikeluarkan 
oleh Jambeck et al (2015) yang menyebutkan produksi sampah plastik di Indonesia mencapai 1,29 Juta metrik ton per tahun, berada diurutan kedua setelah China, yang mencapai 3,53 Juta metrik ton per tahun, Sementara negara-negara lainnya kurang dari 1 juta metrik ton per tahun. (www.mongabay.co.id tanggal 22 Februari 2019). Pencemaran plastik di laut dikuatkan dengan fakta pada tanggal 18 November 2018 adanya penemuan seekor paus sperma (Physeter macrocephalus) yang ditemukan meninggal di pesisir pantai di sekitar Pulau Kapota Kabupaten Wakatobi. Paus dengan panjang 9,5 m dan lebar 1,82 $\mathrm{m}$. Saat ditemukan bangkai paus ini dikelilingi sampah plastik dan potongan kayu. Saat dibelah di dalam tubuh paus ini ditemukan sampah plastik sekitar $6 \mathrm{~kg}$. (https://m.liputan6.com tanggal 28 November 2018).

Di atas adalah salah satu kasus yang muncul terkait dengan sampah plastik. Pemerintah Indonesia telah berupaya untuk mengurangi sampah melalui regulasi maupun tindakan,seperti pembatasan timbulan sampah, pendaurulangan sampah dan pemanfaatan kembali sampah (UU No.18Tahun 2008 serta PP No. 81 Tahun 2012 tentang Pengelolaan Sampah Rumah Tangga dan Sampah Jenis Rumah Tangga), hingga kebijakan kantong plastik berbayar, dimana setiap pasar ritel modern di seluruh Indonesia menetapkan harga $\mathrm{Rp} 200$ untuk setiap pembelian kantong belanja plastik. Masyarakat dihimbau membawakantong belanja sendiri.

Di Samarinda sendiri Pemerintah Kota Samarinda telah mengeluarkan Peraturan Walikota Nomor 1 Tahun 2019 tentang Pengurangan Penggunaan Kantong Plastik. Adapun tujuan dari Perwali yang dimaksud adalah:

a. melindungi wilayah Daerah dari pencemaran dan/atau kerusakan lingkungan yang diakibatkan oleh penggunaan kantong plastik karena sifat bahannya yang tidak mudah terurai oleh alam dan dapat meracuni tanah;

b. menjamin kelangsungan kehidupan makhluk hidup dan kelestarian ekosistem;

c. menjamin keselamatan, kesehatan, dan kehidupan warga Daerah dari ancaman pencemaran dan/atau kerusakan lingkungan hidup, yang disebabkan oleh penggunaan kantong plastik;

d. menjaga kelestarian fungsi lingkungan hidup;

e. mencapai keserasian, keselarasan, dan keseimbangan lingkungan hidup;

Kota Samarinda dengan luas wilayah $718 \mathrm{~km}^{2}$ merupakan daerah yang sebagian besar wilayahnya rawan banjir, karena sekitar $42,77 \%$ berada pada ketinggian 7-25 mdpl. (topologi cenderung landai), disertai rendahnya partisipasi masyarakat dalam pengelolan sampah, serta kebijakan pemerintah memberikan izin tambang batubara dengan metode open pit. Sehingga permasalahan banjir di Kota Samarinda berkorelasi langsung dengan timbulan sampah yang tidak terkelola.

Rendahnya partisipasi masyarakat dalam pengelolaan sampah dapat disebabkan, antara lain kurangnya pengetahuan dalam mengelola sampah yang dihasilkan, kebiasaan untuk mengabaikan kebersihan lingkungan, atau kurang tersedianya tempat penampung sampah (TPS) yang memadai. Dengan demikian sampah plastik bukan persolan pemakaian kantong plastik namun sebagai akibat dari perilaku manusia yang tidak patuh dalam menjaga kebersihan lingkungan dan juga kurang tersedianya TPS.

Agar tujuan Perwali No. 1 tahun 2019 dapat tercapai, maka pemerintah Kota Samarinda mengeluarkan instruksi larangan bagi usaha perdagangan menyediakan kantong plastik bagi konsumen. Hanya saja dengan menerapkan regulasi ini dengan tidak mempertimbangkan berbagai aspek, terutama aspek sosial, dan ekonomi secara lengkap justru telah menimbulkan persoalan di masyarakat. Masih minimnya ketersediaan sarana prsarana tempat sampah di tempat-tempat umum, ketiadaan kantong plastik tanpa menyediakan kantong pengganti membuat masyarakat enggan berbelanja banyak di kios-kios atau toko-toko kecil, hingga peningkatan pengeluaran rumah tangga yang meningkat karena harus membeli kantung plastik sendiri untuk berbelanja atau membuang sampah rumah tangga. Kenyataan yang terjadi bahwa di badan-badan sungai/jalan maupun selokan-selokan masih nampak tumpukan sampah plastik. 
Merujuk pada definisi kebijakan yang disampaikan oleh Timtuss dalam Nawawi (2009) kebijakan sebagai prinsip-prinsip yang mengatur tindakan yang diarahkan kepada tujuan-tujuan tertentu. Kebijakansenantiasa berorientasi kepada masalah (problem oriented) dan berorientasi pada tindakan (action oriented). Nampak bahwa kebijakan adalah suatu ketetapan yang memuat prinsip-prinsip untuk mengarahkan cara-cara bertindak yang dibuat secara terencana dan konsisten dalam mencapai tujuan tertentuArtinya kebijakan Pemerintah Kota Samarinda untuk mengurangi kantong plastik belum mengenai sasaran yang diharapkan, sehingga perlu dikaji lebih lanjut.

\section{TINJAUAN PUSTAKA Struktur Kebijakan Publik}

Pemerintah selaku pihak yang mengambil kebijakan dalam pelaksanaan pembangunan, seyogyanya mampu menyeimbangkan antara aspek ekonomi, sosial, dan lingkungan. Untuk itu, kebijakan yang diambil bermuara pada kepentingan masyarakat baik dalam jangka pendek, jangka menengah maupun jangka panjang. Di sinilah diperlukan kemampuan pemerintah dalam menjalankan fungsi-fungsi manajemen (meliputi: perencanaan, pengorganisasian, pelaksanaan, dan pengawasan/pengendalian) secara terintegrasi satu dengan lainnya. Henry Fayol menyebutkan ada 14 prinsip dalam pelaksanaan manajemen yang baik, meliputi:

1) Pembagian kerja yang berimbang

2) Pemberian kewenangan dan rasa tanggung jawab yang tegas dan jelas

3) Disiplin

4) Kesatuan perintah

5) Kesatuan arah

6) Mengabdikan kepentingan sendiri untuk kepentingan umum

7) Pengajian pegawai

8) Pemusatan koordinasi

9) Jenjang bertingkat/hierarki

10) Ketertiban

11) Keadilan

12) Stabilitas jabatan dalam kepegawaian

13) Prakarsa

14) Semangat kesatuan

Model manajemen yang diterapkan pemerintah harus dilembagakan agar terstruktur, professional dan perencanaannya terukur. Pelembagaan atau pengorganisasian juga berguna untuk mendesain pelaku perencanaan. Actuating adalah bagaimana mengimplementasikan perencanaan yang telah dibuat dan indicator kesuksesannya. Controlling adalah bagaimana mengevaluasi perencanaan yang telah ditetapkan (Nasution, 2012). Pertimbanganpertimbangan yang dilakukan dalam manajemen yang diterapkan pemerintah akan berujung pada keputusan publik.

Keputusan publik adalah sejenis keputusan dan mewakili pilihan sadar, tindakan sukarela, hasil akhir dari musyawarah, kegiatan pengambil keputusan, dengan sebagai objek kegiatan publik (Leoveanu, 2013). Pembuat kebijakan harus rasional. Tapi itu tidak mudah. Agar rasional maka harus ada:

1) identifikasi dan penentuan tujuan;

2) pemeringkatan sasaran menurut urutan kepentingan;

3) identifikasi kemungkinan alternatif kebijakan untuk mencapai tujuan tersebut; dan

4) analisis biaya-manfaat dari alternatif kebijakan.

Karena itu pembuat kebijakan yang terikat pada pembuatan kebijakan rasional harus:

1) mengetahui semua preferensi nilai masyarakat dan bobot relatifnya;

2) mengklarifikasi tujuan dan sasaran dan peringkat mereka; 
3) mengetahui semua kebijakan dan kebijakan yang tersedia;

4) konsekuensi dari setiap alternatif kebijakan;

5) menghitung rasio 'yang dicapai dengan mengorbankan nilai-nilai sosial untuk setiap kebijakan, alternatif; dan

6) memilih alternatif kebijakan efisien inost yang sesuai dengan tujuan.

Ada beberapa model dalam proses pengambilan keputusan terkait dengan kebijakan publik, anatara lain adalah model rasionalis. Model rasionalis cocok diterapkan untuk menghasilkan timndakan inovatif.

Adapun Proses pengambilan keputusan berdasarkan model rasionalis, terdiri dari tahapan berikut (Mercier, 2008):

1) Mengidentifikasi nilai dan tujuan yang dicapai;

2) Menganalisa semua alternatif yang mungkin untuk mencapai tujuan;

3) Meneliti dan memilih informasi berdasarkan efisiensi atau efektivitasberbagai alternatif;

4) Membuat perbandingan antara alternatif dan konsekuensinya;

5) Memilih alternatif yang memaksimalkan nilai dan tujuan;

6) Implementasi;

7) Umpan balik.

Sebuah kebijakan publik untuk menyelesaikan persoalan-persoalan yang ada di masyarakat dan bersifat umum. Karena itu kebijakan publik akan berjalan efektif bila mampu mendorong partisipasi masyarakat untuk terlibat lebih banyak di dalamnya. Bentuk partisipasi masyarakat yang diharapkanpun bermacam-macam tergantung pada jenis persoalan dan solusi yang diberikan, diantaranya adalah dengan memberi umpan balik atas kebijakan yang diturunkan.

\section{Proses Inovasi}

Inovatif dalam Kamus Besar Bahasa Indonesia diartikan sebagai bersifat memperkenalkan sesuatu yang baru; ber-sifat pembaruan (kreasi baru). Inovasi (bahasa Inggris: innovation) dapat diartikan sebagai proses dan/atau hasil pengembangan pemanfaatan/ mobilisasi pengetahuan, keterampilan (termasuk keterampilan teknologis) dan pengalaman untuk menciptakan atau memperbaiki produk (barang dan/atau jasa), proses, dan/atau sistem yang baru, yang memberikan nilai yang berarti atau secara signifikan (terutama ekonomi dan sosial).

Karapkali pemerintah atau masyarakat memiliki pemahaman yang sama antara inovasi den kretaifitas. Padahal yang dimaksud dengan inovasi sebagaimana didefinisikan adalah hal-hal yang terkait dengan pembaharuan, pengembangan, keterampilan untuk menciptakan atau memperbaiki. Sementara yang dimaksud dengan kretaifitas sebenarnya adalah kemampuan untuk menciptakan sesuatu. Di sini kreatifitas muncul sebagai tindakan mengapresiasikan diri terhadap suatu masalah dengan berbagai cara yang datang secara spontan sebagai hasil pemikiran. Dampak lingkungan dari suatu aktifitas membutuhkan inovasi sehingga dampak negatif yang timbul dapat diminimalisir dan meningkatkan nilai manfaat bagi manusia dan lingkungannnya. Namun demikian permasalahan sampah juga dapat mendorong munculnya kreatifitas. (Gambar 1).

\section{Sampah Plastik dan Persoalan yang Ditumbulkan}

Sampah berasal dari beberapa tempat, yakni sampah dari pemukiman penduduk dan sampah dari tempat-tempat umum dan perdagangan tempat tempat umum. Hal inimenunjukkan bahwa kehidupan manusia tidak akan pernah lepas dari sampah. Terutama penumpukan sampah yang terjadi di tempat-tempat umum seperti di pasar-pasar dan di tempat-tempat keramaian ataupun yang memiliki aktifitas tinggi. Dari berbagai jenis sampah yang dihasilkan, 
baik pemukiman, tempat-tempat umum maupun industri yang perlu mendapat perhatian adalah sampah plastik dan limbah B3 (Bahan Berbahaya dan beracun). Sampah plastik perlu mendapat perhatian karena barang-barang berbahan plastik kerap sukar untuk dimusnahkan. Produksi utama plastik dunia adalah 270 juta ton. Limbah plastik global adalah 275 juta ton (dan dapat melebihi produksi primer tahunan melalui pemborosan plastik dari tahun-tahun sebelumnya). Limbah plastik yang paling berisiko memasuki lautan dihasilkan pada populasi pesisir (dalam jarak 50 kilometer dari garis pantai); pada tahun 2010 limbah plastik pantai berjumlah 99,5 juta ton. Hanya sampah plastik yang tidak dikelola dengan baik (salah kelola) yang berisiko tinggi bocor ke lingkungan; pada 2010 ini berjumlah 31,9 juta ton. Dari jumlah ini, 8 juta ton - 3\% limbah plastik tahunan global - memasuki lautan (melalui berbagai outlet, termasuk sungai). Diperkirakan 10.000 hingga 100.000 ton plastik berada di perairan permukaan laut (beberapa kali lipat lebih rendah dari input plastik laut).

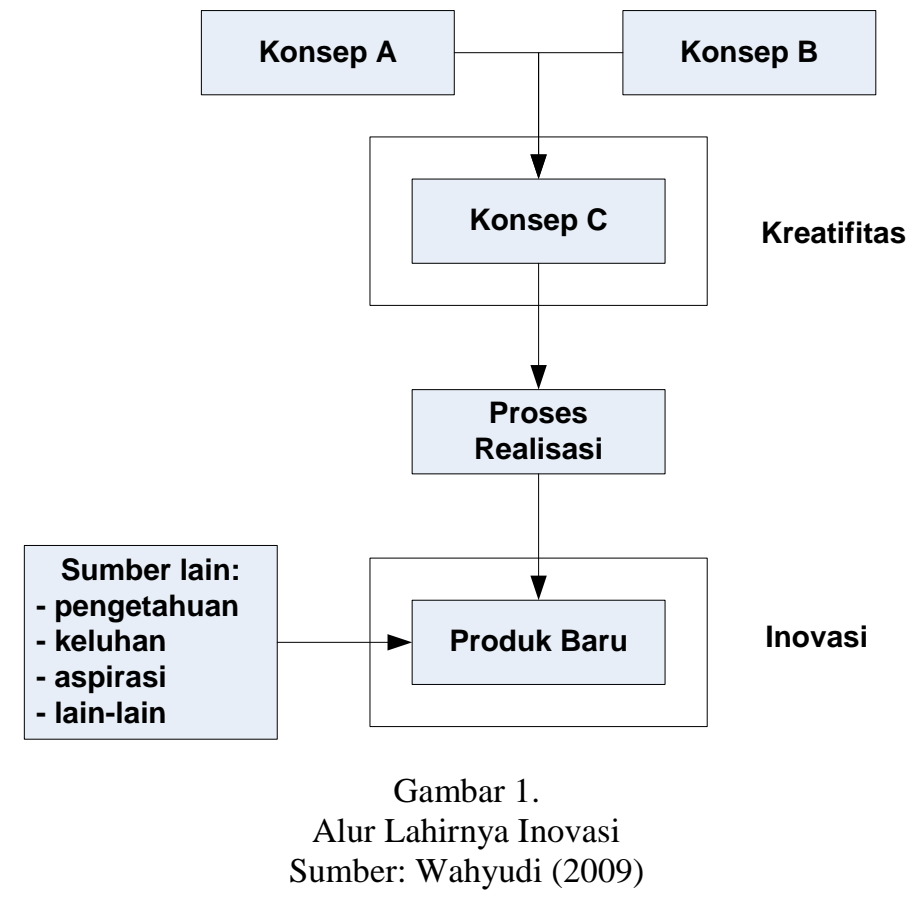

Berdasarkan data yang dirilis Richie and Roser (2018), produksi kumulatif polimer, serat sintetis dan aditif adalah 8.300 juta ton, dengan bentuk pengelolaan sebagai berikut:

1) 2.500 juta ton (30\%) plastik primer masih digunakan pada tahun 2015

2) 4.600 juta ton (55\%) langsung ke TPA atau dibuang;

3) 700 juta ton (8\%) dibakar;

4) 500 juta ton (6\%) didaur ulang (100 juta ton plastik daur ulang masih digunakan;

5) 100 juta ton kemudian dibakar; dan

6) 300 juta ton kemudian dibuang atau dikirim ke TPA.

Diperkirakan ada lebih dari 5 triliun partikel plastik di perairan permukaan dunia. (Eriksen et al, 2014). Penguraian partikel plastik terjadi oleh cekungan laut. Akumulasi sejumlah besar partikel cenderung merupakan hasil dari pemecahan plastik yang lebih besar - ini menghasilkan akumulasi partikel plastik untuk massa tertentu. Partikel-partikel kecil plastik yang masuk ke laut akan di makan oleh binatang-binatang laut hingga mikroorganisme. Ada semakin banyak bukti bahwa konsumsi mikroplastik dapat memengaruhi konsumsi mangsa, yang mengarah pada penipisan energi, menghambat pertumbuhan dan dampak kesuburan. Ketika organisme menelan mikroplastik, ia dapat memakan ruang di usus dan sistem pencernaan, yang mengarah 
pada pengurangan selera makan. Perasaan kenyang ini dapat mengurangi asupan makanan. Bukti dampak penurunan konsumsi makanan, antara lain:

1) laju metabolisme lebih lambat dan kelangsungan hidup di kerang hijau Asia (Ritz and Lenz, 2016);

2) mengurangi reproduksibilitas dan kelangsungan hidup di copepods (Cole et al, 2015)

3) mengurangi pertumbuhan dan perkembangan Daphnia (Ogonowski et al, 2016)

4) mengurangi pertumbuhan dan perkembangan langoustine (Welden and Cowie, 2016)

5) berkurangnya cadangan energi di kepiting pantai dan cacing gelang (Watts and Galloway, 2015; Wright and Galloway,2013).

Di beberapa penelitian menginventarisir dampak negatif dari pencemaran sampah plastik (Anonim, 2016), antara lain sebagai berikut:

1) Pembuangan sampah plastik sembarangan akan mengakibatkan pendangkalan sungai dan aliran sungai, tersumbatnya yang menyebabkan banjir;

2) Tercamarnya air tanah dan tanah;

3) Kantong plastik dakan mengganggu penyerapan air ke dalam tanah;

4) Menurunkan kesuburan tanah;

5) Racun-racun dari partikel plastik yang masuk ke dalam tanah akan membunuh hewan pengurai di dalam tanah (seperti: cacing);

6) Bifenil Poliklorin (PCB) tidak terurai meskipun termakan oleh binatang maupun tanaman akan menjadi racun berantai sesuati urutan makanan.

Pencemaran sampah plastik terjadi karena dibentuk oleh unsur-unsur kimia anrorganik yang sangat lama mengurai Misalnya untuk dapat hancur sempurna, kantong plastik membutuhkan waktu 10 - 12 tahun, botol plastik 20 tahun, dan styrofoam 500 tahun. Mangkok styrofoam 50 tahun, kaleng aluminium 200 tahun, popok 450 tahun, botol plastik 450 tahun, dan tali pancing 600 tahun (Coastal Heritage, 2014). Sementara itu Earth Policy Insitut (2018) menyebutkan usia terurainya beberapa jenis sampah plastik sebagai berikut: Kontainer plastik 50-80 tahun, botol plastik 450 tahun, popok sekali pakai 550 tahun, nilon pancing 600 tahun, dan kantung plastingt $200-1.000$ tahun

Penulis sejalan dengan pendapat Hettiaratachi (2007), yang mengemukakan pandangan terhadap pengelolaan sampah harus berubah dari reaktif menjadi proaktif, yaitu pendekatan holistik yang memperkenalkan bahwa sampah lebih dianggap sebagai sumber daya daripada tanggung jawab. Dalam hal ini, untuk mampu mengatasi masalah sampah plastik, maka perlu dikenali unsur dari pembentuk plastik itu sendiri. Ditinjau dari jenisnya, maka ada tujuh bahan pembentuk plastik yang berpotensi menimbulkan gangguan kesehatan dan pencemaran lingkungan, karena sifatnya yang sukar mengurai atau ada unsur yang berubah bila terkena panas. (Tabel 1).

Dengan demikian penggunaan plastik yang berlebihan dapat mengakibatkan dampak negatif bagi lingkungan.World Economic Forum (2018) merekomendasi langkah-langkah penting yang dapat dilakukan dalam meminimalisir pencemaran akibat plastik, antara lain: mengurangi ketergantungan pada plastik, meningkatkan tanggung jawab produsen, meningkatkan biaya dan pajak untuk plastik yang berpolusi, meningkatkan pengelolaan limbah yang telah menimbulkan masalah besar, implementasi visi nol untuk penggunaan plastik di atas laut, meningkatan penelitian, pemakaian dan pengawasan penggunaan plastik, hentikan aliran sampah plastik ke laut, dan peningkatan dana untuk pembersihan. Dari apa yang diurakan di atas, persoalan sampah plastik tidak hanya menyangkut kuantitas dan kualitas saja namun juga perilaku masyarakat untuk secara tertib membuang sampah plastik pada tempat yang disediakan. Karena itu diperlukan kebijakan yang seimbang antara memotivasi masyarakat untuk patuh dan ketersediaan sarana prasarana pendukung yang menunjang. 
Tabel 1.

Bahan Plastik, Penggunaan dan Bahaya yang Dapat Ditimbulkan

\begin{tabular}{|c|c|c|c|c|}
\hline No. & Nama Bahan & Penggunaan & Bahaya Yang ditimbulkan & Keterangan \\
\hline 1. & $\begin{array}{l}\text { Polyehylene Terephthalate (PET) (Thiela et } \\
\text { al, 2007) }\end{array}$ & $\begin{array}{l}\text { Kemasan botol minuman } \\
\text { ringan }\end{array}$ & $\begin{array}{l}\text { Secara umum PET aman bagi } \\
\text { manusia, namun terdapat masalah } \\
\text { pada antimoni. Antimoni } \\
\text { merupakan sebuah unsur metalloid } \\
\text { yang mengandung racun yang } \\
\text { dapat bocor sewaktu-waktu dari } \\
\text { PET ketika mencapai suhu tertentu. } \\
\text { Antimoni dapat menyebabkan } \\
\text { penyakit kronis dan akut, seperti: } \\
\text { diare, muntah-mundath dan tukak } \\
\text { lambung. }\end{array}$ & \\
\hline 2. & $\begin{array}{l}\text { High Density Polyethylene (HDPE) } \\
\text { (www.kemasanenergy.com, 2019) }\end{array}$ & $\begin{array}{l}\text { Kosmetik, bahan } \\
\text { pembersih rumah tangga. }\end{array}$ & $\begin{array}{l}\text { Merupakan bahan plastik dengan } \\
\text { tingkat bahaya yang rendah. } \\
\text { Plastik HDPE merupakan produk } \\
\text { yang paling banyak mengeluarkan } \\
\text { senyawa kimia estrogenik. Bahan } \\
\text { kimia yang mengandung } \\
\text { estregonik aktif (EA) diduga dapat } \\
\text { menyebabkan masalah kesehatan } \\
\text { terutama pada janin dan anak-anak. }\end{array}$ & $\begin{array}{l}\text { Paparan EA } \\
\text { dapat } \\
\text { mengubah } \\
\text { struktur sel } \\
\text { manusia. } \\
\text { Paparan EA } \\
\text { dapat terjadi } \\
\text { ketika plastik } \\
\text { terkena air } \\
\text { mendidih, } \\
\text { sinar } \\
\text { matahari } \\
\text { (UV) dan } \\
\text { pemamasan } \\
\text { Microwave. }\end{array}$ \\
\hline 3. & Polyvinyl Clorida $(P V C)$ & $\begin{array}{l}\text { Kemasan wadah obat- } \\
\text { obatan, pipa, perabot } \\
\text { rumah tangga. }\end{array}$ & $\begin{array}{l}\text { Bahan mengandung PVC } \\
\text { memungkinkan dapat mengganggu } \\
\text { sistem imunologi dan pernapasan. }\end{array}$ & \\
\hline 4. & $\begin{array}{l}\text { Low Density Polyethylene (LDPE) } \\
\text { (Malpass, 2010) }\end{array}$ & $\begin{array}{l}\text { Ditemukan pada bungkus } \\
\text { roti, makanan beku, pelapis } \\
\text { kertas kotak susu dan cup } \\
\text { untuk minuman dingin atau } \\
\text { panas. Wadah penutup } \\
\text {,aninan dan botol yang } \\
\text { dapat dipencet (misal: } \\
\text { untuk madu dan saus } \\
\text { mustard) }\end{array}$ & $\begin{array}{l}\text { Bahan dengan tingkat bahaya yang } \\
\text { rendah. }\end{array}$ & \\
\hline 5. & $\begin{array}{l}\text { Polypropylene }(P P) \\
\text { (www.bpf.co.uk/plastipedia/polimer/) }\end{array}$ & $\begin{array}{l}\text { Digunakan sebagai wadah } \\
\text { yogurt, margarin, bungkus } \\
\text { makanan siap saji, botol } \\
\text { obat-obatan, tutup botol, } \\
\text { botol untuk saus tomat dan } \\
\text { sirup. }\end{array}$ & $\begin{array}{l}\text { Merupakan jenis plastik yang } \\
\text { aman. }\end{array}$ & \\
\hline 6. & $\begin{array}{l}\text { Polystyrene (PS) atau styrofoam } \\
\text { (www.chemicalsafetyfacts.org/polystyrene/) }\end{array}$ & $\begin{array}{l}\text { Umum ditemukan [ada } \\
\text { wadah makanan, seperti } \\
\text { cup, piring dan mangkuk. }\end{array}$ & $\begin{array}{l}\text { PS merupakan jenis yang harus } \\
\text { diwaspadai bahayanya. Styrene } \\
\text { dapat menyebabkan kanker. } \\
\text { Styrene dapat beralso senahai } \\
\text { neurotoksin dalam jangka waktu } \\
\text { yang lama. Juga dapat menjadi } \\
\text { penyebab tumor paru-paru. }\end{array}$ & $\begin{array}{l}\text { Dihindari } \\
\text { dalam } \\
\text { pengemasan } \\
\text { makanan. }\end{array}$ \\
\hline 7. & Plastik 7 (other) & $\begin{array}{l}\text { Terdapat pada botol saus, } \\
\text { bumbu, botol makanan } \\
\text { bayi, gelas anak-anak, } \\
\text { botol air minum, galon air } \\
\text { isi ulang dna kemasan bea } \\
\text { cukai. Plastik tipe ini } \\
\text { dapat termasuk } \\
\text { polycarbonate yang } \\
\text { mengandung bahan kimia } \\
\text { bisphenol A (BPA). }\end{array}$ & $\begin{array}{l}\text { BPA dapat mengkontaminasi } \\
\text { makanan ketika dicuci untuik } \\
\text { digunakan kembali. BPA dapat } \\
\text { meningkatkan risiko gangguan } \\
\text { kesehatan seperti: perubahan } \\
\text { hormonal, memperbesar kelenjar } \\
\text { prostat, dan asma. BPA juga } \\
\text { terkait dengan obesitas, resistensi } \\
\text { insulin, kerusakan sitem saraf yang } \\
\text { dapat menyebabkan autisme. }\end{array}$ & \\
\hline
\end{tabular}

Sumber: tribunnews.com (2016) 


\section{METODE}

\section{Sumber Data}

Data yang dibutuhkan dalam penelitian ini berupa data primer dan data sekunder. Data primer berupa wawancara (dengan narasumber terpilih yang berasal dari pelaku usaha, dan masyarakat) dan obervasi langsung di sepanjang jalan, kawasan pemukiman dan tepi sungai. Sedangkan data sekunder berupa penelusuran literatur (studi kepustakaan) yang berasal dari buku-buku, majalah dan Jurnal Ilmiah.

\section{Penyajian Data}

Data yang dikumpukkan akan disortir dan data terpilih disajikan berupa tabulasi dan grafik.

\section{Teknik Analisis Data}

Analisis data dilakukan secara deskriptif kualitatif menggunakan metode analisis kebijakan (Policy Analysis) model sintesis terfokus (focused synthesis). Model sintesis terfokus mengaitkan tiga hal pokok, yaitu sumber pustaka mutakhir yang relevan, pengalaman peneliti, dan hasil diskusi. Atas dasar itu dihasilkan rekomendasi untuk kebijakan. Berdasarkan temuan-temuan dari sitesis terhadap sumber informasi itu dihasilkan beberapa rekomendasi yang akan digunakan oleh para pembuat kebijakan untuk memecahkan masalah sosial (Danim, 2000). (Gambar 2).

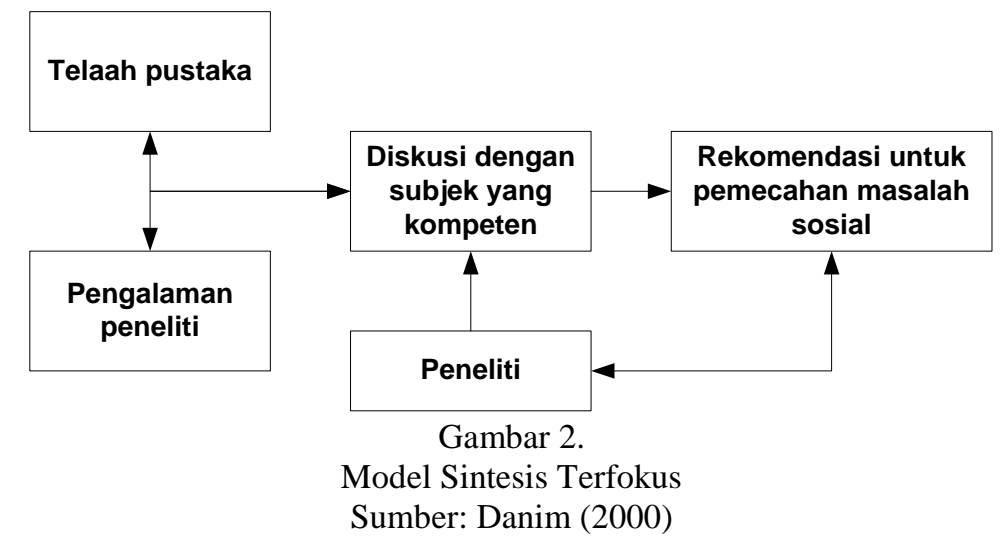

\section{HASIL DAN PEMBAHASAN}

Meningkatnya jumlah sampah yang dihasilkan rumah tangga berkorelasi positif dengan jumlah penduduk, dimana meningkatnya jumlah penduduk di setiap daerah menyebabkanjumlah sampah yang dihasilkan rumah tanggapun semakin meningkat. Terlebih bila sampah yang dihasilkan tidak diimbagi dengan langkah-langkah oinovatif untuk mengatasinya. Data Susenas 2014 menunjukkan bahwaperilaku 3-R masih jarang dilakukan oleh rumahtangga. Persentase rumah tangga yang palingsering memperlakukan sampah dengan mendaurulang $(0,19 \%)$, menjadikan kompos/pupuk $(0,53 \%)$, dimanfaatkan untuk makananhewan $(0,26 \%)$ masih kurang dari $1 \%$. Sementara sekitar $54,65 \%$ rumahtangga paling sering membuang sampah dengancara dibakar. Khusus di Samarinda pada tahun 2015 volume sampah per hari sebanyak $3.133,83 \mathrm{M}^{3}(25,49 \%$ berupa sampah anorganik) meningkat menjadi $3.212,66 \mathrm{M}^{3}(26,17 \%$ berupa sampah anorganik) pada tahun 2016. (Statistik Lingkungan Hidup Indonesia, 2017).

Meskipun secara jelas di Pasal 6 Perwali No. 1 Tahun 2019 bahwa Setiap pelaku usaha dan/atau penyedia kantong plastik berkewajiban:

a. menyediakan kantong plastik ramah lingkungan dan/atau kantong alternatif ramah lingkungan lainnya berdasarkan Standar Nasional Indonesia (SNI) yang ditetapkan oleh Kementerian yang membidangi urusan lingkungan hidup; 
b. menolak melayani konsumen yang membawa kantong plastik yang tidak ramah lingkungan.

Kenyataan yang ada kedua aturan tersebut sukar dilaksanakan. Malah diterjemahkan oleh beberapa pemilik toko untuk tidak menyediakan kantong plastik bagi konsumen.

Prinsip-prinsip pengelolaan lingkungan hidup dengan 3R (Reuce, Reduce, Recycle) merupakan dasar dalam melakukan tindakan untuk mengatasi masalah sampah di Kota Samarinda.Pemerintah Kota Samarinda tidak hanya cukup melihat persoalan pengunaan plastik dari satu aspek saja, yaitu banyaknya penggunaan kantong plastik. Tapi juga melihat kebiasaan masyarakat yang menggunakan barang-barang yang mengandung plastik karena kemampuan/ daya beli dan ketersediaan kebutuhan di pasar.

Pengurangan penggunaan kantorng plastik tanpa mengurangi penggunaan barang-barang berbahan plastik tidak akan berpengaruh signifikan terhadap penurunan pencemaran lingkungan. Namun, demikian perlu ada upaya nyata yang dapat mendorong masyarakat untuk melakukan aktivitas inovatif. Untuk itu diperlukan adanya pendampingan terhadap kelompokkelompok masyarakat yang menghasilkan sampah plastik dalam jumlah besar, dan pengawasan bagi sektor industri.

Inovasi dalam mengatasi sampah plastik dilakukan bukan hanya mengurangi penggunanan barang-barang berbahan plastik tapi dengan penanganan yang tepat dan menjadikan produk olahan yang bernilai ekonomi akan dapat menumbuhkan kreatifitas. Misalnya: menjadikan suatu jenis barang menjadi multi guna (contoh: kantong tempat belanja bisa digunakan sebagai kantongan tempat sampah atau untuk menyimpan barang-barang rumah tangga agar tidak berceceran). Selain itu, masih ada berbagai inovasi yang dapat dilakukan untuk mengatasi masalah sampah plastik dengan cara-cara yang lebih inovasi, antara lain inovasi mengubah botol plastik bekas atau botol PET (Polyethylene Therepthalate) menjadi kertas mineral atau kertas peta. Dengan memanfaatkan teknologi "Cronology"dapat menghemat hingga 20 pohon dan 56.000 liter air 1 ton kertas mineral dapat dibuat dengan $235 \mathrm{Kg}$ pelet (pecahan plastik), dalam waktu 8 jam (Febriansyah, 2019). Bentuk-bentuk inovasi yang dilakukan untuk meminimalisir sampah plastik telah banyak dilakukan di berbagai negara (https://newplasticseconomy.org)

Penggunaan plastik sendiri dalam jangka panjang cenderung meningkat, namun bila dikelola dengan carab-cara yang inovatif justru akan memberi manfaat yang berarti bagi kehidupan. Hal ini dapat digambarkan pada Gambar 3 dan Gambar 4.

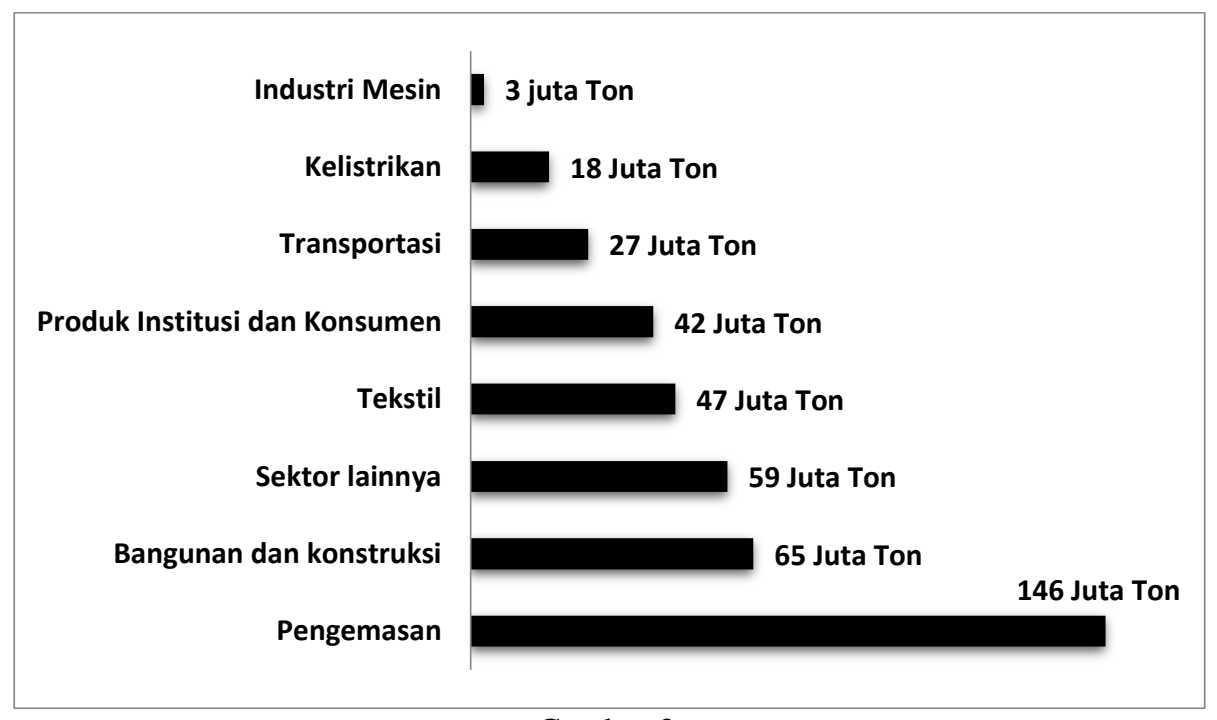

Gambar 3.

Sektor-sektor Pengguna Plastik Terbesar

Sumber: Geyer et al (2017) 


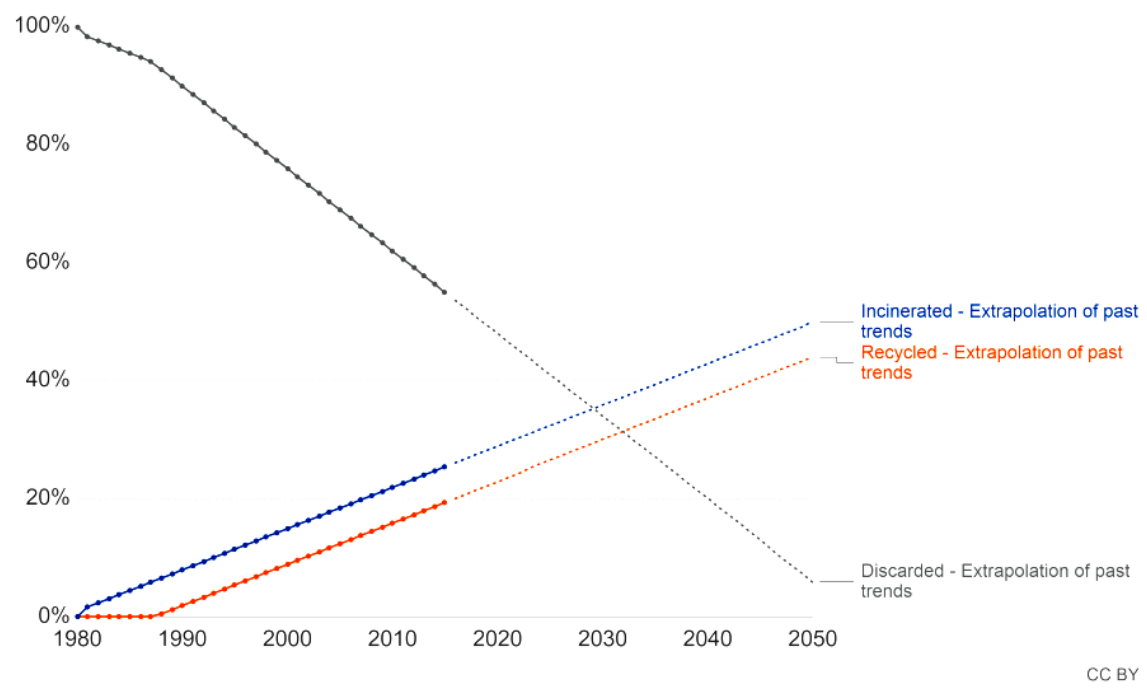

Gambar 4.

Trend Pengelolaan Sampah Plastik

Sumber: Geyer et al (2017)

Pemerintah Kota Samarinda dapat membuat kebijakan yang bersifat edukasi bagi pelakupelaku usaha perdagangan untuk melakukan pelayanan kepada konsumen dengan tetap menyediakan kantongan belanja yang mudah terurai, dengan tidak membiarkan barang-barang belanjaan berceceran ataupun menyibukkan konsumen membawa tas belanja ke mana-mana. Pengeluaran produsen yang semula digunakan untuk berbelanja kantong plastik dapat dialokasikan ke penyediaan kantong belanja yang terbuat dari kertas atau dus yang dibuat dengan cara-cara yang kreatif. Respon dari konsumen yang tidak disediakan kantongan belanja akan cenderung membeli kantongan tersendiri akan berdampak pada peningkatan penggunaan kantong plastik.

Cara lain mengatasi masalah sampah plastik adalah dengan tindakan pemerintah yang mewajibkan pelaku usaha untuk menyediakan tempat-tempat sampah yang memadai di tempattempat yang mudah terlihat dan terjangkau, dan tentu saja pemerintah juga harus menyediakan tempat sampah di lokasi-lokasi keramian atau yang sering dikunjungi masyarakat dengan jumlah yang cukup dan dalam kondisi baik. Misalnya di sepanjang tepian Mahakam membutuhkan 1 buah tempat sampah per 50 meter. Serta memberi papan peringatan bagi masyarakat tidak membuang langsung sampah (plastik) langsung ke badan sungai. Bila pemerintah kota Samarinda hanya melarang pedagang menyediakan kantong plastik, tanpa solusi justru akan berimplikasi pada berkurangnya konsumen. Pedagang akan secara bertahap ditinggalkan konsumennya, karena konsumen merasa cukup kerepotan bila harus membawa sendiri tas belanjaan. Di sini kondisi psikologis konsumen cukup terganggu dengan aturan yang dibuat. Dengan demikian kebijakan yang membentuk manajemen inovasi sangat diperlukan dalam mengatasi pemasalahan sampah plastik di Samarinda.

\section{KESIMPULAN}

Dari hasil penelitian dapat ditarik kesimpulan bahwa kebijakan pemerintah Kota Samarinda dalam mengatasi masalah sampah plastik belum mengacu pada manajemen inovasi yang dapat mendorong pada tumbuhnya kreatifitas di masyarakat maupun pelaku usaha.Kebijakan yang dibuat berpotensi hilangnya konsumen bagi pedagang yang tidak menyediakan kantongan belanja. Sarana-prasarana pembuangan sampah di tempat-tempat umum perlu dievaluasi karena memang belum memadai. Karena itu, pemerintah Kota Samarinda perlu mengkaji kembali pelarangan penyediaan kantong plastik untuk konsumen 
tanpa melibatkan kerangka berpikir manajemen inovasi yang justru dapat meningkatkan sampah plastik di masyarakat.

\section{UCAPAN TERIMAKASIH}

Penulis mengucapkan terima kasih kepada pihak-pihak yang telah memberi informasi yang dibutuhkan, serta bagi reviewer yang berkenan mereview manuskrip ini untuk layak diterbitkan.

\section{DAFTAR PUSTAKA}

Anonim (2016). Bahaya Pencemaran Sampah Plastik dan Cara Penanggulangannya. www.kompasiana.com, diakses 29 November 2016.

Coastal Heritage (2014). The Global Plastic Breakdown; How Microplastics are shredding Ocean Health. South Carolina: Sea Grant Consortium.

Cole, M., Lindeque, P., Fileman, E., Halsband, C. \& Galloway, T. (2015) The impact of polystyrene microplastics on feeding, function and fecundity in the marine copepod Calanus helgolandicus. Environment, Science \& Technology, (49): 1130-1137

Danim, S (2007). Pengantar Studi penelitian Kebijakan. Jakarta: Bumi Aksara.

Erikson, M; Labreton, L.C; Carson, H.S; Thiel, M; Moore, C.J; Borerro, J.C; and Reiser, J (2014). Plastic Pollution in the world's oceans: more than 5 trilion plastic pieces wighing over 250.000 tins afloat at sea. PloS.one, 9 (12).

Febriansyah (2019). Inovasi Baru Mengubah Sampah Plastik Jadi Kertas yang Mudah Terurai, https://tirto.id/inovasi-baru-mengubah-sampah-plastik-jadi-kertas-yang-mudahterurai-dftk diakses tanggal 19 April 2019

Geyer, R; Jambeck, J.R; and Law K.L. (2017). Production, use and fate all plastics ever made. Science Advances 3 (7): e1700782.

Hettiaratachi, J.P.A (2007). New Trends in Waste Management: North American Percpective. Proceddings of the International Conference on Sustainable Solid Waste management, 5 7 September 2007, Chenna. India. Pp: 9 - 14.

Jambeck, J. R; Geyer, R; Wileox, C; Siegler, T.R; perryman, M; Andrady, A; Narayan, R; Law, K.L (2015). Plastic Waste inputs from land into the Ocean. www.sciencemag.org. Vol. 347.

Leoveanu, A.C (2013). Rationalist Model In Public Decision Making. Journal of Public Administration, Finance and Law. Issue 4/2013. Pp: 43-54.

Malpass, D (2010). Introduction to Industrial Polyethylene, Catalysts, and Processes. New York: John Wiley and Sons.

Mercier, J. (2008). L' administration publique - De l'École classique au nouveau management public, Quebec, Les presses de l' Université Laval, 6e triage

Nasution, A. Z (2012). Pendekatan Ekosistem Dalam Pembangunan Berkelanjutan. https://bangazul.com/prinsip-prinsip-pembangunan-berkelanjutan-2/ diakses 7 Mei 2019.

Nawawi, I (2009). Public Policy (Analisis, Strategi, Advokasi teori dan praktek).Surabaya: PMN. 
Ogonowski, M., Schür, C., Jarsén, Å. and Gorokhova, (2016). The effects of natural and anthropogenic microparticles on individual fitness in Daphnia magna. PLoS ONE, 11, e0155063

Pemerintah Republik Indonesia (2019). Peraturan Walikota Nomor 1 Tahun 2019 tentang Pengurangan Penggunaan Kantong Plastik. Berita Daerah Kota Samarinda Tahun 2019 Nomor 1.

Rist, S.E and Lenz, M (2016). Suspended microsized PVC particles impair the performance and decrease survival in the Asian green mussel Perna vidis. Marine Pollution Bulletin. Vol. 111 Issue 1 - 2. Pp: 213 - 220

Ritchie, H and Roser, M (2018). Plastic Pollution, https://ourworlddata.org.diakses tanggal 20 April 2019.

Thiele, U.K (2007). Polyester Bottle Resins Production, Processing, Properties and Recycling. PETplanet Publisher GmbH, Heidelberg, Germany. Pp. 259.

Wahyudi, A (2009). Inovasi dan Kreatifitas dalam Dari Budaya Kerja menuju Kinerja Organisasi. Samarinda: PKP2A III LAN Samarinda.

Watts, A. J. R., Urbina, M. A., Corr, S., Lewis, C. and Galloway, T. S. (2015). Ingestion of plastic microfibers by the crab Carcinus maenas and its effect on food consumption and energy balance. Environment, Science \& Technology, (49): 14597-14604

Welden, N. A. C. and Cowie, P. R. (2016). Environment and gut morphology influence microplastic retention in langoustine, Nephrops norvegicus. Environmental Pollution, (214): 859-865

World Economic Forum (2008). Eight Steps to solve the Ocean plastic problem. https://www.weforum.org/agenda/2018/03/8-steps-to-solve-the-oceans-plasticproblem/, diakses tanggal 19 April 2019.

Wright, S., Rowe, D., Thompson, R. C. and Galloway, T. S. (2013). Microplastic ingestion decreases energy reserves in marine worms. Current Biology. (23): 1031-1033. 